\title{
Protection against Whole Body $\gamma$-Irradiation Induced Oxidative Stress and Clastogenic Damage in Mice by Ginger Essential Oil
}

\author{
Kottarapat Jeena $^{1}$, Vijayasteltar B Liju ${ }^{1}$, Viswanathan Ramanath ${ }^{2}$, Ramadasan \\ Kuttan $^{1 *}$
}

\begin{abstract}
Radioprotective effects of ginger essential oil (GEO) on mortality, body weight alteration, hematological parameters, antioxidant status and chromosomal damage were studied in irradiated mice. Regression analysis of survival data in mice exposed to radiation yielded LD50/30 as 7.12 and 10.14 Gy for control (irradiation alone) and experimental (GEO-treated irradiated) mice, respectively, with a dose reduction factor (DRF) of 1.42. In mice exposed to whole-body gamma-irradiation (6 Gy), GEO pre-treatment at 100 and $500 \mathrm{mg} / \mathrm{kg}$ b.wt (orally) significantly ameliorated decreased hematological and immunological parameters. Radiation induced reduction in intestinal tissue antioxidant enzyme levels such as superoxide dismutase, catalase, glutathione peroxidase and glutathione was also reversed following administration of GEO. Tissue architecture of small intestine which was damaged following irradiation was improved upon administration of GEO. Anticlastogenic effects of GEO were studied by micronuclei assay, chromosomal aberration and alkaline gel electrophoresis assay. GEO significantly decreased the formation of micronuclei, increased the $\mathrm{P} / \mathrm{N}$ ratio, inhibited the formation of chromosomal aberrations and protected agaisnt cellular DNA damage in bone marrow cells as revealed by comet assay. These results are supportive of use of GEO as a potential radioprotective compound.
\end{abstract}

Keywords: Ginger essential oil- radioprotection- dose reduction factor- comet assay-chromosomal

Asian Pac J Cancer Prev, 17 (3), 1325-1332

\section{Introduction}

Ionizing radiations has been shown to induce DNA damage, which can lead to mutagenesis and carcinogenesis (Ronald et al., 2008). Growing concern for the protection of biological systems against radiation induced damages and genotoxicity, has promoted radiation research to develop effectual radioprotectors. Exposure to ionizing radiation causes deleterious effects to living tissues both by direct (interaction between radiation and target macromolecules) or indirect (due to the products released during aqueous radiolysis) effects (Draganic and Draganic, 1971). This in turn leads to excess production of reactive oxygen species (ROS), whose interactions in the biological system can damage the cellular antioxidant defense mechanisms and also cause mutations and chromosomal aberrations (Weiss and Landauer, 2003).

The development of effective radioprotective agents is of great importance in view of their potential application during exposure of human population to natural background radiations, occupational and medical exposures, nuclear industry as well as nuclear warfare (Xu et al., 2014). Radiotherapy has also become an important modality in the treatment of cancer. Various drugs of natural and synthetic origin, i.e., immune modulators ( $\gamma$-interferon), DNA binding molecules, natural antioxidants (vitamin A, C and E), biological response modifiers such as cytokines, immune stimulators, etc. were found to provide good radioprotection (Harikumar and Kuttan., 2004; Ping et al., 2007). WR 2721 (amifostine), a highly expensive, synthetic compound, is the only Food and Drug Administration (FDA) approved radioprotective drug for clinical use during radiotherapy. However, it has restrained utilization at therapeutic levels due to severe side effects and toxicity associated with recurrent usage (Wang et al., 2014). The use of plants and natural products as radioprotectors has spurred interest due to their low toxicity and minimum side effects.

Ginger (Zingiber officinale $R$ ), belonging to the family Zingiberaceae, is a common medicinal and aromatic plant indigenous to South eastern Asia and Central America. Ginger is used as a culinary herb and also as a traditional remedy for various ailments. The essential oil isolated from ginger by steam distillation is known to possess antibacterial, antiviral and antifungal activities (Singh et al., 2005; Koch et al., 2008). It is also reported to have antioxidant, ant-inflammatory, and antinociceptive activity (Vendruscolo et al., 2006; Jeena et al., 2013). 
Previous work conducted in our laboratory has shown the antimutagenic, antiulcer and anticarcinogenic properties of ginger essential oil (Jeena et al., 2014). The present study was conducted to evaluate the radioprotective and anticlastogenic potential of ginger essential oil.

\section{Materials and Methods}

\section{Animals}

Male Balb/C mice (6-8 week old, $25 \pm 3 \mathrm{~g}$ weight) were purchased from Small Animal Breeding Station, Kerala Agricultural University, Thrissur, Kerala, India. They were housed in well-ventilated polypropylene cages under controlled temperature, and humidity, and were provided with normal mouse chow (Sai Durga Feeds and Foods, Bangalore) and water ad libitum. Animal experiments were conducted after getting prior permission from Institutional Animal Ethics Committee (IAEC) and as per the instructions prescribed by the Committee for the Purpose of Control and Supervision of Experiments on Animals (CPCSEA), Ministry of Environment and Forest, Government of India.

\section{Chemicals}

Dithiobis-2-nitrobenzoic acid (DTNB), reduced glutathione (GSH), and colchicine were obtained from Sisco Research Laboratories, Mumbai, India. High melting point agarose and low melting agarose were purchased from Sigma Aldrich Inc.USA. May Grunwald and Giemsa stains were obtained from Merck, India. All other chemicals and reagents used were of analytical grade.

\section{Ginger essential oil (GEO)}

GEO was provided by Kancore Ingredients Limited., Angamali, Kerala, India. GEO was dissolved in paraffin oil for all the studies. Composition of ginger essential oil was determined using a Hewlett-Packard gas chromatograph (Model 6890) coupled with a quadruple mass spectrometer (Model HP 5973) and a HP - 5MS capillary column $(5 \%$ phenylmethylsiloxane; $30 \mathrm{~m} \times$ $320 \mathrm{U} \mathrm{m} \times 0.25 \mathrm{U} \mathrm{m}$ ). The interphase, ion source and selective mass detector temperatures were maintained at $243^{\circ} \mathrm{C}, 230^{\circ} \mathrm{C}$ and $150^{\circ} \mathrm{C}$, respectively. Helium was used as a carrier gas at a flow rate of $1.4 \mathrm{~mL} / \mathrm{min}$. The oven temperature was programmed linearly at $60^{\circ} \mathrm{C}$; then increased from $60^{\circ} \mathrm{C}$ to $243^{\circ} \mathrm{C}$ at the rate of $3^{\circ} \mathrm{C} / \mathrm{min}$. The components present in GEO were identified using the National Institute of Standards Technology (NIST) library search facility provided with the data analysis software supplied along with GC/MS system.

Major components identified in GEO were ó-zingiberene $(31.08 \%)$, followed by ar-curcumene $(15.4 \%)$ and $\alpha$-sesquiphellandrene $(14.02 \%)$. The minor ingredients included bisabolene $(13.80 \%)$ and sabinene (8.27\%) (Jeena et al., 2011).

\section{Irradiation}

The source of radiation was a Cobalt-60 Theatron Phoenix Teletherapy Unit (Atomic Energy Ltd., Ottawa, Canada) in the Department of Radiotherapy, Amala Cancer
Hospital and Research Centre, Kerala. Unanaesthetised animals were restrained in well-ventilated boxes and whole body was exposed at a dose rate of $1.44 \mathrm{~Gy} /$ minute in a field size of $25 \times 25 \mathrm{~cm}^{2}$ at a distance of $80 \mathrm{~cm}$ from the source.

Assessment of radioprotective potential of GEO in irradiated mice

Effect of GEO on $\gamma$-radiation-induced mortality and body weight alterations of mice

Seventy eight healthy male Balb/C mice were divided into thirteen groups. (i) Control group-irradiation alone. (ii) Vehicle control group- animals of this group received paraffin oil of equivalent amount GEO for 5 consecutive days prior to radiation. (iii) Experimental group (GEO+irradiation) the animals were given $500 \mathrm{mg} /$ $\mathrm{kg}$ b.wt for 5 consecutive days prior to radiation. Previous works have established $500 \mathrm{mg} / \mathrm{kg}$ b.wt given orally was the nontoxic and appropriate minimum dose level of GEO (Jeena et al., 2011). On the 6th day, $1 \mathrm{hr}$ after last administration of paraffin oil or GEO, all the animals were exposed to $6,8,10$ or 12 Gy radiation. GEO and paraffin oil administrations were continued for another 14 days after irradiation. The animals were observed daily for up to 30 days past irradiation for mortality and body weights of survivors were recorded every $3^{\text {rd }}$ day.

Percentage of mice survived up to 30 days of exposure against each radiation dose was used to construct survival dose response curves.

\section{Calculation of Dose Reduction Factor (DRF)}

To determine the protective ratio of GEO against lethal gamma irradiation, the DRF was calculated by dividing the LD50/30 of GEO treated animals by the LD50/30 of animals without any treatment.

\section{Protection of hematological system by GEO}

Thirty male Balb/C mice were divided into five groups consisting of six animals each. Group I was unirradiated control, group II - irradiated control [whole body exposure to $\gamma$-radiation $(6 \mathrm{~Gy})$ ], group III- irradiated control treated with vehicle (paraffin oil), group IV- irradiated animals treated with $100 \mathrm{mg} / \mathrm{kg}$ b.wt GEO, orally, group $\mathrm{V}$ - irradiated animals treated with $500 \mathrm{mg} / \mathrm{kg}$ b.wt GEO, orally. Animals in group IV and V were pretreated with GEO five days prior to radiation. All the animals except group I was exposed to whole body radiation 600 rads (6 Gy) and treatment in groups III, IV and V were continued for 14 days.

Blood was collected into heparinized tubes from the caudal vein at $24,48,96 \mathrm{hrs}$ after irradiation and on the $7^{\text {th }}$ and $14^{\text {th }}$ day. The total WBC count was checked using hemocytometer and hemoglobin was estimated by cyanmethemoglobin using Drabkin's method (Drabkin and Austin, 1932).

\section{Protection of hematopoietic system by GEO}

Thirty male Balb/C mice were taken and grouped and the treatment regime followed as the above experiment. Animals were sacrificed by cervical dislocation on the $3^{\text {rd }}$, $7^{\text {th }}$ and $14^{\text {th }}$ day after irradiation. Femurs of all the animals 
were taken at the time of sacrifice and bone marrow was collected into the PBS containing $10 \%$ fetal calf serum (FCS). The number of $\alpha$-esterase positive cells was determined by the azo dye coupling method (Bancroft and Cook, 1992). The numbers of $\alpha$-esterase positive cells were expressed out of 4000 cells. The bone marrow cell number was determined using a hemocytometer and expressed as total live cells/femur.

\section{Protection of antioxidant system by GEO}

The jejunal portion of the small intestine was cut and the intestinal mucosa was scraped with a sterile glass slide and $25 \%$ homogenate was prepared using ice cold $0.1 \mathrm{M}$ Tris- $\mathrm{HCl}$ buffer ( $\mathrm{pH}$ 7.4). The homogenates were centrifuged at 10,000 rpm for $30 \mathrm{~min}$ at $40 \mathrm{C}$. The supernatants obtained were used for the estimation of antioxidant enzymes. Superoxide radical scavenging activity was determined by the NBT reduction method (McCord and Fridovich, 1969). Catalase was estimated by measuring the rate of decomposition of hydrogen peroxide at $240 \mathrm{~nm}$ (Aebi, 1974). Glutathione levels were estimated by the method of Moron et al. (1979). Glutathione peroxidase activity was determined based on the degradation of $\mathrm{H} 2 \mathrm{O} 2$ in the presence of GSH (Hafeman et al., 1974). The total protein content was estimated by method of Lowry et al. 1951).

\section{Histopathological analysis}

The jejunal portion of the intestine was cut and taken for histopathological analysis. After removal, the tissue was washed in PBS and fixed in $10 \%$ formaldehyde. The tissue was embedded in paraffin wax and five micron thick sections were made. The sections were then stained with hematoxylin, counter-stained with eosin and sections were scored for the following parameters: villus height, number of villi, goblet cells, mucosal erosion, inflammatory cells and basement membrane, etc.

\section{Assessment of anticlastogenic effect of GEO Inhibition of micronuclei formation}

Fifteen male Balb/C mice were divided into 5 groups of three animals each. Group I was normal without any treatment. Group II-radiation control (whole body $\gamma$ -radiation 1.5 Gy), group III- radiation + vehicle (paraffin oil), group IV - radiation $+100 \mathrm{mg} / \mathrm{kg}$ b.wt GEO, group $\mathrm{V}$ - radiation $+500 \mathrm{mg} / \mathrm{kg}$ b.wt GEO. Animals in group III, IV and V were given paraffin oil and GEO, orally, for five days. On the 6th day all the animals in group II-V received whole body $\gamma$-radiation $(1.5 \mathrm{~Gy} /$ animal $)$. All the animals were killed by cervical dislocation about $24 \mathrm{~h}$ after $\gamma$-irradiation, and bone marrow smears (four slides per mouse) were prepared and stained with May-Grunwald/ Giemsa (Schmid 1975). The number of micronucleated polychromatic erythrocytes (MnPCEs) in 2000 PCEs per mouse was determined.

\section{Inhibition of chromosomal aberrations}

Fifteen Balb/C mice were taken and grouped as the above experiment. The animals in groups III, IV and V were pretreated with paraffin oil or GEO for five days. Animals in group II-V received a single exposure of whole body $\gamma$-radiation of $3 \mathrm{~Gy}$ on the 6 th day. The animals were sacrificed by cervical dislocation $24 \mathrm{hrs}$ after irradiation. All the animals were injected (i.p.) with colchicine (2 $\mathrm{mg} / \mathrm{kg} \mathrm{b.wt)} 1.5 \mathrm{~h}$ prior to sacrifice. The bone marrow cells were collected from both the femurs by flushing with phosphate buffered saline (PBS) containing 10\% fetal calf serum. A total of 300 metaphase chromosomes were scored per animal. Different types of aberrations like chromatid breaks, chromosome breaks, fragments, rings and dicentrics were scored.

\section{Alkaline single cell gel electrophoresis (comet assay)}

Thirty male Balb/C mice were divided into five groups consisting of six animals each. Group I-normal, Group II - radiation alone, group III- radiation + paraffin oil (vehicle control group), group IV- radiation $+100 \mathrm{mg} / \mathrm{kg}$ b.wt GEO and group V-radiation $+500 \mathrm{mg} / \mathrm{kg}$ b.wt GEO. GEO was administered orally 5 days prior to radiation. Animals in group II-V received a single dose of whole body radiation (4 Gy/animal).

Immediately after irradiation, animals were killed by cervical dislocation and bone marrow cells were collected. The alkaline comet assay was carried out based on the original work of Singh et al. (2000) with minor modifications (Nair and Salvi, 2005). The slides were dried and stained with $30 \mu \mathrm{L}$ ethidium bromide (1X) staining solution and the comets were visualized immediately at a 400X magnification using an Olympus BX50 fluorescence microscope. The extent and distribution of DNA damage indicated by the comet assay was evaluated by examining at least 100 randomly selected comets per slide and analyzed using 'CASP' software which gives \%DNA in tail, tail length, tail moment and olive tail moment directly (Konca et al., 2003).

\section{Statistical analysis}

All data were expressed as mean \pm standard deviation (SD). Significance levels of comparison of differences were determined by one-way ANOVA followed by posthoc Dunnett's multiple comparison tests using Graphpad Instat 3 software. Regression analysis was done to obtain LD50/30 values and to determine the DRF.

\section{Results}

\section{Radioprotective effects of ginger essential oil} Effect of GEO on $\gamma$-radiation-induced mortality and body weight alterations of mice

There was a radiation dose dependent survival of mice in control and the experimental groups as shown in Figure1(a). Complete mortality was seen on days 3, 6 and 21 in the control and vehicle control groups, when exposed to 12,10 and $8 \mathrm{~Gy}$ respectively. The first deaths were recorded on days 2, 4 and 16 at 12, 10 and 8 Gy respectively. All the animals exposed to $6 \mathrm{~Gy}$ were found to be alive on the 30th day, indicating that $6 \mathrm{~Gy} \gamma$-radiation is not a lethal dose to these mice.

Administration of GEO significantly enhanced the survival of mice exposed to different doses of gamma radiation. In the group exposed to $12 \mathrm{~Gy}$ radiation, the first death was recorded on day 5 and $16 \%$ of animals 
Kottarapat Jeena et al

survived for 30 days. In 10 Gy irradiated group, death of the animals started on the 13th day after irradiation and $50 \%$ of the animals survived till the end of the experiment. Mortality of animals commenced only 28th day for 8 Gy exposed animals and $67 \%$ of animals survived in the group after 30 days.

There was a profound loss in body weight of animals treated with 10 and 12 Gy $\gamma$-radiations, GEO pretreatment showed an increase in body weight. Exposure of mice to 6 and $8 \mathrm{~Gy} \gamma$-radiation also reduced the body weight of animals and GEO treatment significantly increased the loss of body weight in a dose-dependent manner (data not shown).

Radiation dose reduction factor $(D R F)$ in the mice treated with GEO

Radiation dose-response curves for mice with or without pretreatment of GEO are shown in Figure 1(b). The LD50/30 for control (irradiation alone) and experimental (GEO pretreated irradiated) animals was computed as 7.12 and $10.14 \mathrm{~Gy}$ respectively. On the basis of LD50/30 survivability, GEO pretreatment produced a dose reduction factor of 1.42 .

Effect of GEO on hematological parameters of irradiated mice

A marked decline in total WBC count was observed in irradiated and vehicle control groups at $24 \mathrm{hr}(2650 \pm 541)$ which was further decreased on day 4 . In GEO pre-treated irradiated group IV and V animals, WBC counts were

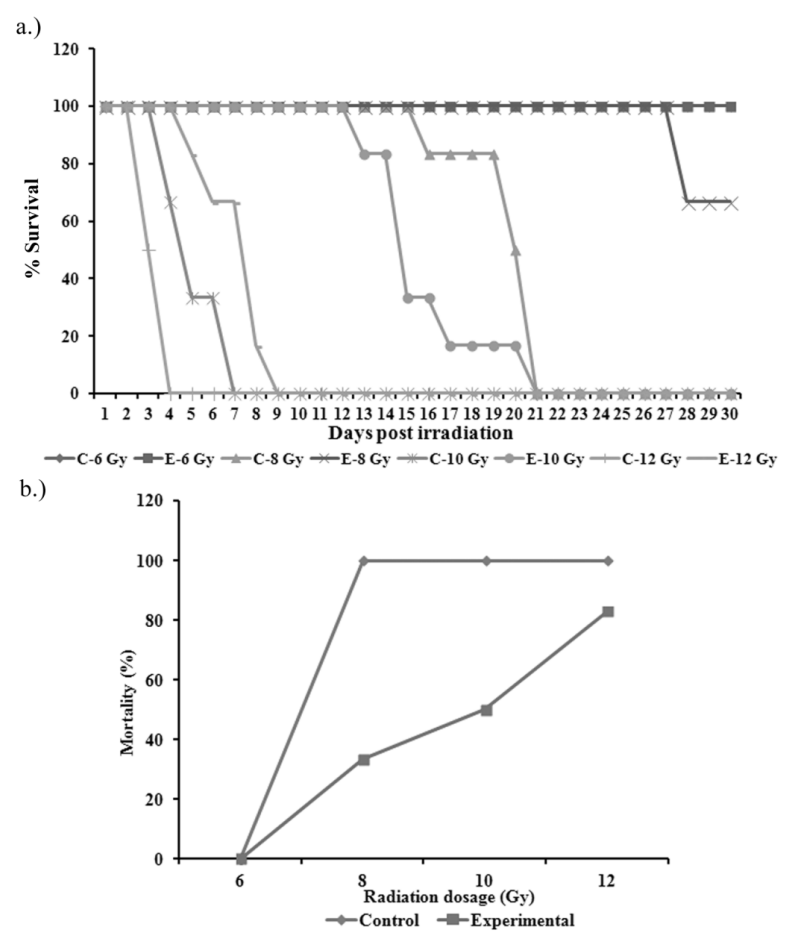

Figure 1. (a). Survival percentage of mice at different doses of gamma radiation, with (E-experimental) and without (C-control) ginger essential oil. (b) Percentage mortality within 30 days post-irradiation, with (experimental) and without (control) ginger essential oil (LD50/30 estimation)

Table 1. Effect of Ginger Essential Oil Administration on Radiation Induced Micronuclei Formation in Mice Bone Marrow Cells

\begin{tabular}{lcccccc}
\hline \multicolumn{1}{c}{ Groups } & $\%$ MnPCE & $\%$ MnNCE & $\%($ MnPCE + MnNCE $)$ & $\%$ PCE & $\%$ NCE & P/N ratio \\
\hline Normal & $0.33 \pm 0.58$ & $0.02 \pm 0.01$ & $0.35 \pm 0.57$ & $27 \pm 2$ & $73 \pm 2$ & $0.37 \pm 0.06$ \\
Radiation alone & $3.33 \pm 0.61$ & $0.21 \pm 0.03$ & $3.55 \pm 0.56$ & $16.33 \pm 1.53$ & $88.67 \pm 1.53$ & $0.20 \pm 0.02$ \\
Vehicle control & $2 \pm 1$ & $0.22 \pm 0.02$ & $2.22 \pm 0.99$ & $17.33 \pm 2.1$ & $83.33 \pm 2.08$ & $0.21 \pm 0.02$ \\
$100 \mathrm{mg} / \mathrm{kg}$ b.wt & $2.78 \pm 0.30 \mathrm{~ns}$ & $0.04 \pm 0.01 * * *$ & $2.82 \pm 0.30^{\mathrm{ns}}$ & $21.67 \pm 2.08^{* *}$ & $78.33 \pm 2.08$ & $0.28 \pm 0.03 * *$ \\
GEO & & & & & \\
$500 \mathrm{mg} / \mathrm{kg}$ b.wt & $0.70 \pm 0.05^{* * *}$ & $0.02 \pm 0.01^{* * *}$ & $0.72 \pm 0.06^{* *}$ & $25.67 \pm 2.08^{* * *}$ & $74.33 \pm 3$ & $0.35 \pm 0.04 * * *$ \\
GEO & & & & & & \\
\hline
\end{tabular}

*Each value represents the mean \pm S.D $(n=3)$. **p<0.01 compared with vehicle control, ***p<0.001 compared with vehicle control. MnPCE, Micronucleated polychromatic erythrocytes; MnNCE, Micronucleated normochromatic erythrocytes; PCE, Polychromatic erythrocytes; NCE, normochromatic erythrocytes.

Table 2. Effect of Ginger Essential Oil on Radiation Induced Chromosomal Aberrations in Mouse Bone Marrow Cells

\begin{tabular}{|c|c|c|c|c|c|c|c|}
\hline Groups & $\begin{array}{l}\text { Chromosome } \\
\text { fragments }\end{array}$ & $\begin{array}{c}\text { Chromosome } \\
\text { breaks }\end{array}$ & $\begin{array}{l}\text { Chromatid } \\
\text { breaks }\end{array}$ & Dicentrics & Rings & $\begin{array}{c}\text { Total } \\
\text { aberrations }\end{array}$ & $\%$ aberrations \\
\hline Normal & $0.33 \pm 0.58$ & $1 \pm 0$ & $1 \pm 1$ & 0 & 0 & $2.33 \pm 1.58$ & $0.78 \pm 0.53$ \\
\hline $\begin{array}{l}\text { Radiation } \\
\text { alone }\end{array}$ & $27 \pm 6.24$ & $20 \pm 2$ & $34.99 \pm 9.3$ & $7.33 \pm 1.53$ & $10.67 \pm 3.06$ & $99.33 \pm 22.12$ & $33.11 \pm 7.37$ \\
\hline $\begin{array}{l}\text { Vehicle } \\
\text { control }\end{array}$ & $28.33 \pm 5.69$ & $20 \pm 2$ & $38 \pm 4.58$ & $7 \pm 1$ & $67 \pm 2.52$ & $103 \pm 15.79$ & $34.33 \pm 5.26$ \\
\hline $\begin{array}{l}100 \mathrm{mg} / \mathrm{kg} \\
\text { b.wt GEO }\end{array}$ & $13.33 \pm 2.08 * * *$ & $13 \pm 3.61 * *$ & $13 \pm 2 * * *$ & $4.67 \pm 1.53 *$ & $5 \pm 2 * *$ & $49 \pm 11.21 * * *$ & $16.33 \pm 3.74 * * *$ \\
\hline $\begin{array}{l}500 \mathrm{mg} / \mathrm{kg} \\
\text { b.wt GEO }\end{array}$ & $7.67 \pm 2.52 * * *$ & $8.67 \pm 2.52 * * *$ & $11 \pm 2.65 * * *$ & $2.33 \pm 1.53 * * *$ & $1.33 \pm 1.53 * * *$ & $31 \pm 10.73 * * *$ & $10.33 \pm 3.58 * * *$ \\
\hline
\end{tabular}

Each value represents the mean \pm S.D $(n=3) . * * \mathrm{p}<0.01$ compared with vehicle control, $* * * \mathrm{p}<0.001$ compared with vehicle control 
found to be significantly higher than the corresponding control group throughout the study (Figure 2a).

Hemoglobin concentration in irradiated and vehicle control treated mice (Group II and III) showed the maximum decrease on day $3(8.56 \pm 1.51)$. Animals irradiated with GEO pre-treatment (Group IV and V) exhibited a higher hemoglobin concentration compared to irradiated groups and values were found to be near normal by the end of the experiment (Figure 2b).

\section{Effect of GEO on hematopoietic parameters of irradiated} mice

The number of $\alpha$-esterase positive cells were found to be drastically decreased following irradiation. Administration of GEO (100 and $500 \mathrm{mg} / \mathrm{kg} \mathrm{b.wt)}$ significantly increased the number of cells with $\alpha$-esterase activity to almost normal values by day 14 (Figure 2c). GEO (100 and $500 \mathrm{mg} / \mathrm{kg}$ b.wt) was also found to increase the bone marrow cellularity $(\mathrm{p}<0.001)$ at all the three time points as compared to the irradiated and vehicle treated
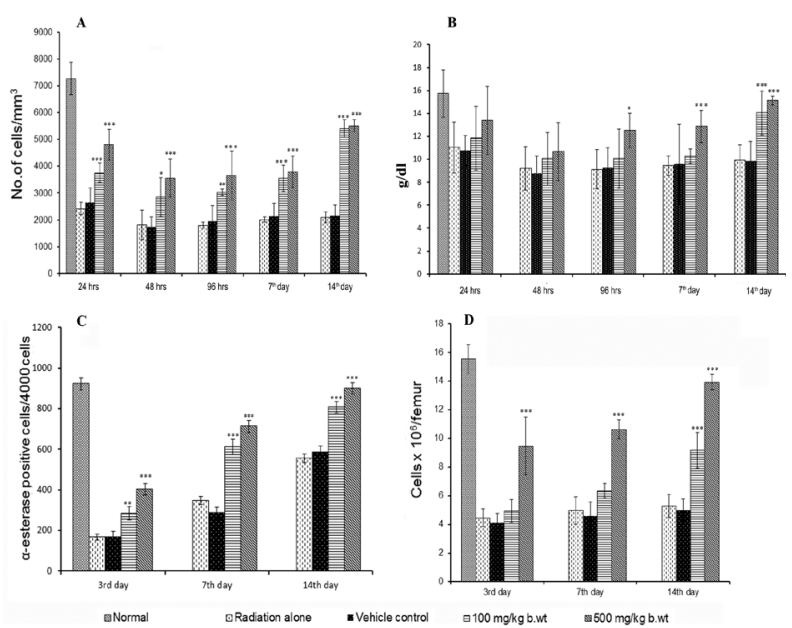

Figure 2. Effect of Administration of Ginger Essential Oil on Hematopoiesis of Irradiated Mice. Mice were pretreated with ginger essential oil at different doses five days prior to irradiation (6 Gy, single dose). (a). Total number of WBC in pretreated and untreated irradiated mice at different time points.(b). Hemoglobin concentration in pretreated and untreated irradiated mice at different time points. (c). $\alpha$-esterase activity in pretreated and untreated mice at different days following irradiation. (d).Bone marrow cellularity in in pretreated and untreated irradiated mice at different days following irradiation. Each value represents the mean \pm S.D $(n=6) . * p<0.05, * * p<0.01$ compared with vehicle control, ${ }^{* * *} \mathrm{p}<0.001$ compared to vehicle control group group (Figure 2d).

Effect of GEO on antioxidant status of small intestine mисоsa

Whole body $\gamma$-radiation reduced all the antioxidant defense mechanisms in the small intestine. The activity of SOD was which was reduced in the small intestine of mice was significantly $(\mathrm{p}<0.001)$ elevated upon administration of GEO by the 14th day (Figure 3 a). Continuous administration of GEO significantly increased the levels of catalase enzyme as compared to the irradiated group in small intestine mucosa (Figure 3b). GPx enzyme levels were significantly reduced in small intestine mucosa after radiation. GEO pretreated irradiated animals significantly elevated in enzyme levels in a dose dependent manner compared to irradiated animals by the $14^{\text {th }}$ day (Figure 3c). A marked enhancement in the levels of GSH was observed from the $7^{\text {th }}$ day post irradiation in GEO treated groups (Figure 3d).

Histopathological analysis of intestinal mucosa of irradiated mice

The effect of GEO on $\gamma$-radiation induced gastrointestinal damage was evaluated on the $7^{\text {th }}$ day post
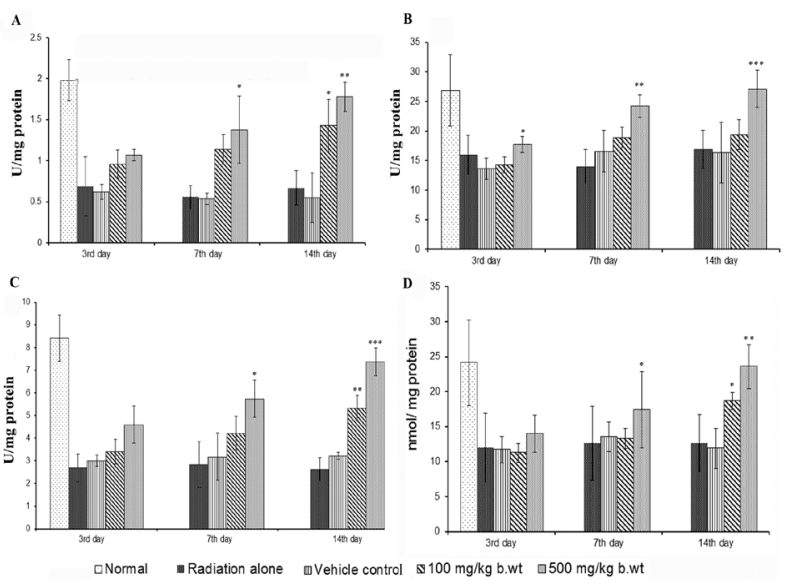

Figure 3. Effect of Administration of Ginger Essential Oil on Antioxidant Enzyme Profiles of Intestinal Mucosa of Irradiated Mice. Mice were pretreated with ginger essential oil at different doses five days prior to irradiation (6 Gy, single dose). (a). SOD enzyme activity (b). catalase (c). glutathione peroxidase (d). GSH. Each value represents the mean $\pm S . D(n=6) . * p<0.05$, **p $<0.01$ compared with vehicle control, $* * * \mathrm{p}<0.001$ compared to vehicle control group

Table 3. Comet Parameters Presenting the effect of Ginger Essential oil (GEO) Administration on $\gamma$-radiation (4 Gy) Induced DNA Strand Breaks in Bone Marrow of Balb/C mice

\begin{tabular}{lcccc}
\hline \multicolumn{1}{c}{ Groups } & \%DNA in tail & Tail length & Tail moment & Olive tail moment \\
\hline Normal & $1.8 \pm 0.3$ & $3.8 \pm 0.77$ & $0.3 \pm 0.01$ & $0.6 \pm 0.01$ \\
Radiation alone & $9 \pm 1.2$ & $6.2 \pm 1$ & $1.8 \pm 0.01$ & $1.3 \pm 0.06$ \\
Vehicle control & $9.5 \pm 1.7$ & $5.9 \pm 0.8$ & $1.6 \pm 0.06$ & $2 \pm 0.05$ \\
$100 \mathrm{mg} / \mathrm{kg}$ b.wt GEO & $4.3 \pm 0.4 * * *$ & $4.3 \pm 0.6^{* *}$ & $1 \pm 0.02^{*}$ & $0.9 \pm 0.02^{*}$ \\
$500 \mathrm{mg} / \mathrm{kg}$ b.wt GEO & $2.1 \pm 0.7^{* * *}$ & $4 \pm 0.3^{* * *}$ & $0.8 \pm 0.03^{* *}$ & $0.7 \pm 0.03^{* * *}$ \\
\hline
\end{tabular}

Each value represents the mean \pm S.D $(n=6)$. $* \mathrm{p}<0.05, * * \mathrm{p}<0.01$ compared with vehicle control, ***p<0.001 compared to vehicle control group. 


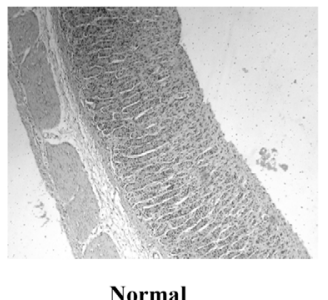

Normal

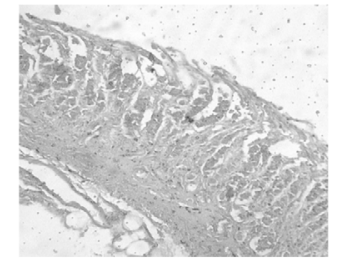

Radiation alone

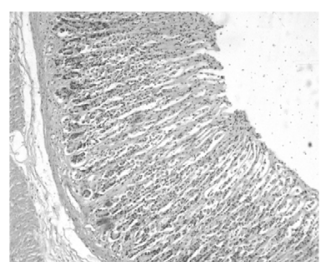

Radiation treated +

GEO (500 mg/kg b.wt)

Figure 4. Histopathological analysis of small intestine of mice. (a). normal small intestine (b). small intestine exposed to $6 \mathrm{~Gy}$ (single dose) irradiation (c). small intestine pretreated with ginger essential oil $(500 \mathrm{mg} /$ kg b.wt) and exposed to $6 \mathrm{~Gy}$ irradiation

irradiation. Radiation reduced the number of glands, villi and villi height when compared to normal intestinal cells (Figure 4a). The section of intestine showed ulceration of mucosa in some places with the floors of the ulcerated areas showing inflammatory exudates. Mucosa, submucosa and muscularis mucosa showed diffuse infiltration by lymphocytes, plasma cells and a few polymorphs (Figure $4 \mathrm{~b})$. The section of intestine treated with GEO $(500 \mathrm{mg} /$ $\mathrm{kg}$ b.wt) showed normal mucosal glands and villi lined by mucin secreting columnar epithelium (Figure 4c).

\section{Anticlastogenic effect of ginger essential oil}

Effect on GEO on radiation induced micronuclei formation

Whole body radiation resulted in significant increase in MPCE $(3.33 \pm 0.58)$ and MNNCE $(0.21 \pm 0.03)$. The percentage of micro nucleated polychromatic erythrocytes (MNPCE) were $2.78 \pm 0.30$ and $0.70 \pm 0.05(\mathrm{p}<0.01)$ for 100 and $500 \mathrm{mg} / \mathrm{kg}$ b.wt GEO treated group of animals while in normal it was $0.33 \pm 0.58$. The percentage of micro nucleated normochromatic erythrocytes (MNNCE) was found to be $0.04 \pm 0.001$ and $0.02 \pm 0.01(\mathrm{p}<0.001)$ for 100 and $500 \mathrm{mg} / \mathrm{kg}$ b.wt GEO treated group of animals while it was $0.02 \pm 0.03$ for normal animals. The $\mathrm{P} / \mathrm{N}$ ratio was significantly decreased from normal level of $0.37 \pm$ 0.06 to $0.20 \pm 0.02$ in irradiated group of animals. The $\mathrm{P} / \mathrm{N}$ ratio increased to $0.35 \pm 0.04(\mathrm{p}<0.001)$ in $500 \mathrm{mg} / \mathrm{kg}$ b.wt treated animals by administration of the GEO (Table 1).

\section{Effect on GEO on radiation induced chromosomal aberrations}

Radiation produced a significant increase in the percent aberrant cells $(33.11 \pm 7.37)$ compared to normal $(0.78$ $\pm 0.53)$. A corresponding increase was found in all the individual aberrations. Treatment with GEO (100 and 500 $\mathrm{mg} / \mathrm{kg} \mathrm{b.wt}$ ) and irradiation resulted in significant decrease in the percent chromosomal aberration like chromatid breaks, rings, chromosome fragments and dicentrics in bone marrow cells (Table 2). The percent aberrant cells were also decreased to $16.33 \pm 3.74$ in $100 \mathrm{mg} / \mathrm{kg} \mathrm{b}$.wt and $10.33 \pm 3.58$ in $500 \mathrm{mg} / \mathrm{kg}$ b.wt GEO treated group of animals.

\section{Effect on GEO on radiation induced DNA strand breaks} in bone marrow

Whole body $\gamma$-radiation (4 Gy) resulted in damage to genomic DNA in bone marrow as reflected by the increase in comet parameters such as \%DNA in tail, tail length, tail moment and olive tail moment (Table 3). The administration of GEO significantly brought down the levels of these parameters. Thus, the cellular DNA of bone marrow was found to be protected by the administration of GEO.

\section{Discussion}

Ionizing radiations are being used in a multitude of arenas, and the planned (radiotherapy) and unplanned radiation exposures to the public domain have always been associated with some skepticism. Most of the cellular alterations induced by ionizing radiations are indirect and mediated by generation of free radicals (Londhe et al., 2009). These free radicals disturb the endogenous antioxidant systems and interfere with the genetic structure, leading to apoptosis and cell death. An integrated system of endogenous enzymatic, non enzymatic and repair mechanisms protects the body from damages caused by reactive oxygen species (ROS). However, when these mechanisms becomes defective or insufficient, the use of natural or synthetic radioprotective compounds are of utmost importance in radiation therapy because normal tissues should be protected against radiation injury while using higher doses of radiation to obtain better cancer control.

Ionizing radiations are highly cytotoxic towards cells with high rate of proliferation. Whole body irradiation drastically impairs normal physiological processes in rapidly proliferating cells of the hematopoietic system, gastrointestinal system, etc. Radiation induced damages to cells and various tissues results in organ failures, loss of body weight and ultimately death. Survival data from the present study indicate that pre-treatment with GEO protected mice from the lethal effects of ionizing radiation. Mortality was found to be delayed in all the GEO pretreated groups at all the radiation dosages administered. Magnitude of radioprotective effect of GEO was demonstrated by determining the LD50/30 (DRF = 1.42), which is a standard method to determine the efficacy of a radioprotective agent.

Exposure to whole body radiation caused suppression in hematopoiesis, immunosuppression and mylosuppression resulting in decreased production of blood cells (Machova et al., 2002). Protective effect was also seen in the case of bone marrow cellularity and $\alpha$-esterase positive cells (an indicator of maturing monocytes), demonstrating its effect on stem cell proliferation. Thus, administration of GEO stimulates or protects hematopoiesis in bone marrow 
as seen by the subsequent increase in the hematological constituents in the peripheral blood of mice.

Intestinal tissue has highly proliferating cells which are radiosensitive. It also has an antioxidant defense mechanism to combat oxidations occurring. The intestinal architecture was found to be completely destroyed by exposure to irradiation. The administration of GEO regained the functional structure of intestinal tissue and thereby protects the tissue from radiation stress. The levels of antioxidant enzymes (SOD, catalase, GPx) and GSH were also found to be restored in intestinal mucosa which shows the protective effect of GEO against gastrointestinal damages.

The antigenotoxic potential of GEO was assayed through micronuclei, chromosomal aberration and comet assay. Chromosomal damages induced by $\gamma$-radiation are mainly due to indirect effects of radiation. Bone marrow cells are very sensitive to radiation which causes chromosomic aberrations and increases the frequency of micronucleated polychromato erythrocytes (MnPCE). GEO significantly inhibited radiation induced DNA breaks in micronuclei as evident from the reduced number of MnPCE. The $\mathrm{P} / \mathrm{N}$ ratio is an indicator of the rate of proliferation of cells and a decrease in the ratio indicates the effect of radiation on the cell cycle by suppression of erythropoiesis (Thulasi et al., 2007). Pretreatment with GEO increased the $\mathrm{P} / \mathrm{N}$ ratio indicating the anticlastogenic potential of GEO. Radiation also produced a significant increase in all types of chromosomal aberrations such as breaks, gaps, ring formations, dicentrics, etc. Pretreatment with GEO was found to significantly decrease these chromosomal aberrations compared to radiation control. This suggests the protective role of GEO against DNA double strand breaks in bone marrow cells.

Alkaline comet assay is an effective technique to study the extent of DNA damage and protection (Gandhi et al., 2004). Ionizing radiations produces lesions in DNA such as single strand breaks, double strand breaks, DNA-DNA cross links, etc which is indicated by the increase in comet parameters (tail length, tail moment, Olive tail moment). Administration of GEO significantly decreased all the comet attributes which indicate GEO's ability to protect cellular DNA from radiation damages.

Natural products as radioprotectors are gaining interest due to their proven therapeutic potential and low toxicity at the effective dose with minimum or no side effects (Song et al., 2006). GEO has proven to be NOEL at $500 \mathrm{mg} / \mathrm{kg}$ b.wt (Jeena et al., 2011). There is considerable evidence suggesting the correlation between antioxidant properties and radioprotection in literature (Indu et al., 2011). GEO possess antioxidant capacity in vivo (Jeena et al., 2013) which may be attributed for its radioprotective potential. The present study provides evidence that GEO mitigates radiation induced effects at molecular, cellular and tissue levels by counteracting both the direct and indirect effects of radiation.

\section{Acknowledgements}

Authors are thankful to Spice Board of India., for providing financial assistance to carry out this work [NO.
$\mathrm{MD} / \mathrm{M}$ and H/01/08-09].

\section{References}

Aebi M (1974). Catalase estimation. In 'Methods of enzymatic analysis', Eds Berg Meyer HV. Verlag, Chemie, New York, 673-84.

Bancroft JD, Cook HF (1984). Manual of Histologic Techniques. Churchill Livingston, London, 171-4.

Drabkin DL, Austin M (1932). Spectrometric studies; spectrometric constants for common haemoglobin derivatives in human, dog and rabbit blood. J Biol Chem, 98, 719-33.

Gandhi NM, Maurya DK, Salvi VP, et al (2004). Radioprotection of DNA by glycyrrhizic acid through scavenging free radicals. J Radiat Res, 45, 461-8.

Gurdip S, Kapoor IPS, Pratibha S, et al (2008). Chemistry, antioxidant and antimicrobial investigations on essential oil and oleoresins of Zingiber officinale. Food Chem Toxicol, 46, 3295-02.

Hafeman DG, Sundae RA, Houestra WG (1974). Effect of dietary selenium on erythrocyte and liver glutathione peroxidase in the rat. $J$ Nutr, 104, 580-7.

Harikumar KB, Kuttan, R (2004). Protective effect of an extract of Phyllanthus amarus against radiation induced damage in mice. J Radiat Res, 45, 133-9.

Indu T, Uma Devi P, Papiya B (2011). Protection against radiation clastogenicity in mouse bone marrow by Phyllanthus niruri. Indian J Exp Biol, 49, 704-10.

Jeena K, Liju VB, Kuttan R (2011). A preliminary 13-week oral toxicity study of ginger oil in male and female wistar rats. Int J Toxicol, 30, 662-70.

Jeena K, Liju VB, Viswanathan R, Kuttan R (2014).Antimutagenic potential and modulation of carcinogen-metabolizing enzymes by ginger essential oil. Phytother Res, 28, 849-55.

Jeena K, Liju VB, Kuttan R (2013). Antioxidant, antiinflammatory and antinociceptive activities of essential oil from ginger. Indian J Physiol Pharmacol, 57, 51-62.

Koch C, Reichling J, Schneele J (2008). Inhibitory effect of essential oils against herpes simplex virus type- 2 . Phytomedicine, 15, 71-80.

Konca K, Lankoff A, Banasik A, et al (2003). A cross platform public domain pc image analysis program for the comet assay. Mutat Res, 534, 15-20.

Londhe JS, Devasagayam TP, Foo LY, et al (2009). Radioprotective properties of polyphenols from Phyllanthus amarus Linn. $J$ Radiat Res, 50, 303-9.

Lowry OH, Rosenbrough NJ, Farr AL, et al (1951). Protein measurement with Folin Wu reagent. J Biol Chem, 193, 265-75.

Mackova P, Fedoroeko (2002). Effect of Liposomal muramyl tripeptide phosphatidylethanolamine and Indomethacin on hematopoietic recovery in irradiated mice. Physiol Res, 51, 511-21.

Mc Cord JM, Fridovich I (1969). Superoxide dismutase enzyme function for erythrocaprein. J Biochem, 244, 6049-56.

Moron MA, Depierre JW, Manner Vick B (1979). Levels of glutathione, glutathione reductase and glutathione-Stransferase activities in rat liver. Biochim Biophys Acta, 582, 67-8.

Nair CKK, Salvi VP (2005). Protection of DNA from gamma radiation induced strand breaks by epicatechin. Mutat Res, 650, 48-54.

Ping X, Junqing J, Junfeng J, et al (2011). Radioprotective effects of troxerutin against gamma irradiation in V79 cells and mice. Asian Pac J Cancer Prev, 12, 2593-6.

Ronald EC, Annette MB, Susan MB, et al (2008). Resveratrol 
Reduces Radiation-Induced Chromosome Aberration Frequencies in Mouse Bone Marrow Cells. Radiat Res, 169, 633-8.

Schmid W (1975). The micronucleus test. Mutat Res, 31, 9-15.

Singh G, Maurya S, Catalan C, et al (2005). Studies on essential oils, Part 42: chemical, antifungal, antimicrobial and sprout suppressant studies on ginger essential oil and its oleoresin. Flavour Frag J, 20, 1-6.

Singh NP (2000). Microgels for estimation of DNA strand breaks, DNA protein crosslinks and apoptosis. Mutat Res, 455, 111-27.

Song LH, Yan HL, Cai DL (2006). Protective effects of soybean isoflavone against gamma-irradiation induced damages in mice. J Radiat Res, 47, 157-65.

Thulasi GP, Damodharan DP (2007). Prevention of radiation -induced chromosome damage in mouse bone marrow by aqueous leaf extract of Chicorium intybus. $J$ Cell Molecular Biol, 6, 59-64.

Vendruscolo A, Takaki I, Bersani-Amado LE, et al (2006). Antiinflammatory and antinociceptive activities of Zingiber officinale Roscoe essential oil in experimental animal models. Ind Jour Pharm, 8, 58-9.

Wang K, Liu C, Di CJ, et al (2014). Kojic acid protects C57BL/6 mice from gamma-irradiation induced damage. Asian Pac $J$ Cancer Prev, 15, 291-7.

Weiss JF, Landauer MR (2003). Protection against ionizing radiation by antioxidants, nutrients and phytochemicals. Toxicol, 189, 1-30.

Xu P, Zhang WB, Cai XH, et al (2014). Flavonoids of Rosa roxburghii Tratt act as radioprotectors. Asian Pac J Cancer Prev, 15, 8171-5. 